\title{
Neural Network Model For Predicting STUDENTS' ACHIEVEMENT IN BLENDED COURSES At THE UNIVERSity OF DAR Es SALAAM
}

\author{
Eliah kazumali and Ellen Kalinga \\ Department of Computer Science and Engineering, University of Dar es Salaam, \\ Tanzania
}

\begin{abstract}
Educator's knowledge about the likely students' achievement in blended courses prior to sitting for examinations provides room for early intervention on students' learning process, especially to those at risk. Unfortunately, Leaning Management Systems (LMSs), Moodle in particular lacks an environment to assist educators access such knowledge from time to time before undertaking their examinations. This raised the need to propose a model, of which from time to time would be providing the likely students' achievement based on activities in Moodle and previous achievement, taking a case of postgraduate programmes at the University of Dar es Salaam.

This study applied artificial neural networks in building a prediction model. Simulations were conducted in Matrix Laboratory (MATLAB) utilizing seventy eight instances (78) of students' logs of three blended courses extracted from Moodle for 2013/2014 and 2014/2015 academic years.

Mean Square Error (MSE) and Coefficient of Determination $\left(R^{2}\right)$ performance metrics were used to find the best prediction model considering ten possible models. The study revealed a model with architecture of 4:10:1 trained with Bayesian Regularization (BR) to be the best model resulting to least MSE of 0.0170 and high $R^{2}$ of 0.93 on training. During testing, the model successfully predicted $78 \%$ of the students' achievement with risk and pass status.
\end{abstract}

\section{KEYWORDS}

Artificial Neural Networks, Moodle logs, Blended Learning, Moodle, Learning Management Systems

\section{INTRODUCTION}

Classroom based learning as a traditional way, has been in practice for quite long time in Higher Learning Institutions (HLIs). Today, the adoption of Learning Management Systems (LMSs) have created chances to improve the traditional way of learning and teaching [1]. LMSs have been adopted in HLIs to either complement classroom based learning sessions with eLearning experiences to form blended learning or fully transform the traditional based learning and teaching into web forming online learning.

The common adopted LMSs in delivering blended or online courses include Moodle, Blackboard, and Sakai. Moreover, Moodle is said to be the most popular open source LMS [2]. As of September 2014, Moodle had over 67 million users distributed in 230 countries across the world supporting various institutions like universities and schools [3]. The UDSM in particular deployed Moodle in 2008 to avoid high cost of annual licensing fee for the proprietary blackboard LMS which was initially deployed in 1998 [4].

DOI : 10.5121/ijaia.2017.8203 
International Journal of Artificial Intelligence and Applications (IJAIA), Vol.8, No.2, March 2017

Blackboard LMS operated at the UDSM for ten years from 1998 to 2008. During this time, the Blackboard LMS was used to complement face to face learning of some courses in programmes. But, it is after migrating to Moodle in 2008 when programmes running entirely in blended delivery mode commenced. Since then, a total of two hundred fifty seven (257) students have been enrolled into blended learning programmes in seven academic years from 2008/2009 to 2014/2015. Therefore, it can be noticed that, blended learning programmes at the UDSM has widened access to education to a number of people, especially those with limited time to attend regular classes.

In traditional classroom settings, educators interact and monitor students more often throughout the learning process. In this case, educators are likely to identify students at risk in the process of learning in advance, hence respond to them in time. But in blended courses where students interact more often with LMS, educators lack such prior knowledge before sitting for their examinations. Thus, bringing unexpected results at the end of the course.

In order to equip educators with prior knowledge, various artificial neural network models have been developed. The models that have been developed relied largely on predictors extracted from admission information such as age, sex and previous achievement. Predictors generated during interactions with Moodle LMS have not been adequately considered despite their significant contributions on students' achievement. Meanwhile, there is proof that, the activities of students in LMS such as forum participations [5], login frequency [6] and topic views [7] have much contributions on students' achievement in blended learning courses. This indicates an existence of correlation between LMS usage and students' achievement which ensures the possibility of constructing a prediction model relying on such activities generated in Moodle.

\section{LITERATURE REVIEW}

\subsection{E-LEARNING AND LMS}

E-Learning has emerged in the past few decades as a result of exploiting technology in education for delivering learning in electronic format, most likely via Internet [8]. Since the deployment of technology in education, shifting from traditional learning practices to eLearning or combining both learning delivery modes have been possible. Some HLIs have opted to mix the traditional classroom based learning with some few eLearning sessions creating the so called blended learning while others shifting all the practices entirely online, creating the so called online learning. But, in making sure that the benefits of traditional computer based is not totally abandoned, most HLIs in Africa tend to adopt blended model of learning [9].

As defined by [10], blended learning is a formal education program in which students learn at least in part through online delivery of content and instruction with some element of student control over time, place and pace. These elements of blended learning provide room to students with limited time to attend and pursue various programmes mostly in HLIs.

Based on the interaction between educators and students, eLearning can be conducted synchronously and asynchronously. Synchronous eLearning environments require tutors and educators to be online at the same time where live interactions like live chats and streamed lectures take place between participants and they must adhere to a rigid schedule provided. Asynchronous eLearning environment is the case where students are logging into and using LMS independently of other students and educators. But, synchronous technologies like streamed lectures are expensive and difficult to implement [11]. As a result in most HLIs such as the University of Dar es Salaam asynchronous learning has been the dominant mode. 
Although blended courses at the UDSM like the course of Engineering Finance and Economics (MG 611), Project Appraisal (MG621) and Statistics and Research Methods (MG 602) appeared to have exploited some synchronous features like live chats, none of them appeared to have lecture live streaming yet. LMSs such as Moodle offer environments to deliver academic courses or other types of training via Internet. Moodle is an asynchronous learning management system [11], as a result, the present study mostly focused on asynchronous features available in Moodle such as forums activities and views.

Many HLIs in Tanzania tend to offer some courses or sometimes all courses belonging in a programme in eLearning mode either synchronously or asynchronously or both. At the UDSM there are number of courses from various programmes which are delivered in blended mode of learning, but, there are specific programmes where all courses are delivered in blended mode. These are Masters in Engineering Management (MEM), Postgraduate Diploma in Engineering Management (PGDEM) and Postgraduate Diploma in Education (PGDE). The present study is making use of courses in programmes currently offered at the UDSM.

\subsection{Predictors Of Students' Achievements In Blended Courses}

Different methodological approaches have been used to predict students' achievement in blended courses. Just like the way it has been possible in weather forecasting, population prediction, price fluctuation prediction, the most common approaches have been traditional statistical methods such as discriminant analysis, decision tree and multiple regressions [12], [13]. Various studies have shown these traditional approaches to lag behind in terms of providing accurate prediction compared to machine learning approaches such as using artificial neural networks [14], [15].

Although artificial neural networks provide accurate predication results than other approaches, the question rises on the suitable variables to be used as predictors of students' achievements in blended courses. Predictors of students' achievement are variables within or outside the learning environment with effects on overall students' achievements in blended courses. Regardless of whatever kind of approach used for prediction, still the precise selection of predictors is important. In case of traditional classroom based learning, various studies have come up with predictors like gender, class attendance, age and previous score in GPA. But, when it comes to blended learning it remains a challenge to find suitable predictors to be used in prediction of students' achievement.

With the adoption of LMS in HLIs to facilitate blended learning, more predictors have been explored as a result of students' activities in LMS. These activities are accumulated in relation to various interactions carried by students in LMS from the start of the course to its end. Such activities like resources viewed, assignments, and online forums are valuable activities since can be used in prediction of students' achievement [16]. These predictors hold some educational data in LMS which are valuable data and can be used for predictions.

Furthermore, the LMS log data where the prediction parameters are extracted, are preferred to be used in prediction because they are difficult or impossible to be apprehended by someone since they can be collected without the knowledge of the educator [6]. In that sense, when such parameters are used for prediction they can provide trustful results. In addition to that, [16] show that, the predictors for students' achievements are not only those associated with students' activities in LMS only, but also from those resulting from classroom such as previous achievement, attendance and participation. Therefore, predictors in blended courses involve combination of predictors from eLearning mode and in traditional classroom setting as presented;

Login Sessions - Measures the extent at which individual students have been engaging in LMS throughout the study. Students tend to login into LMS mainly for the purpose of accessing learning resources, reading and interacting with other students and course educators. 
International Journal of Artificial Intelligence and Applications (IJAIA), Vol.8, No.2, March 2017

Recourses Viewed - Learning resources are developed in text, video, audio and animations formats for being viewed by students.

Forums and chats - Forum being an asynchronous tool is the most popular tools to make students collaborate with themselves and with their educators in LMS environment.

Overall Grade Point Average - Regardless the mode of study, the GPA provides the summary of previous academic achievement of students.

\subsection{Abstract Neural Network Model}

This is the conceptual representation of a neural network. Input neurons (predictor variables) stand for predictors of students' achievement in blended courses, which consist of login sessions, forums participations, number of viewed resources, and overall undergraduate achievement in GPA. The output neuron was formed by grade achievement in a course. A value for each predictor with corresponding course achievement creates a pair in training and testing the neural network. An abstract neural network model for student's achievement in blended courses has been shown in Figure 1.

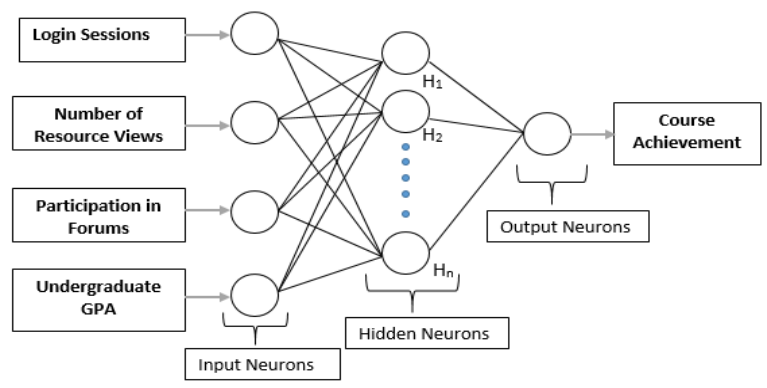

Figure 1: An Abstract Network Model for Predicting Students’ Achievements

\section{METHOD}

\subsection{RESEARCH DESIGN}

The study adopted an experimental research design. This is a quantitative nature of research whereby actual values of input variables (predictor variables) and output variable were gathered and used. Figure 2 shows a summary of the phases adopted in modelling the neural network prediction model as proposed by [19].

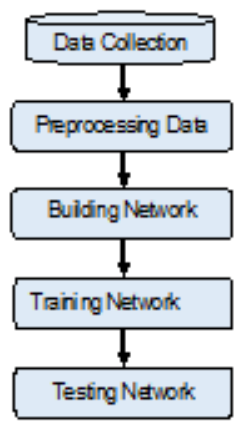

Figure 2: Basic Flow in Neural Network Modelling 
International Journal of Artificial Intelligence and Applications (IJAIA), Vol.8, No.2, March 2017

\subsection{SAMPLE}

The present study used seventy eight (78) students' instances/logs of three courses pursued by students drawn randomly from academic years of 2013/2014 and 2014/2015. This constituted of twenty eight (28) students participated in a course of Engineering Finance and Economics (MG 611), twenty seven (27) in Computer Programming (CS 680), and twenty three (23) in Project Appraisal (MG 621) course.

\subsection{Data Collection}

Students' Moodle logs of three courses were collected, the interest was to collect values of variables/predictors of interest. These were values of login sessions, forum participation frequency, number of resource views and the undergraduate GPA. The output variable was made up with the students' scored in each course. Figure 3 shows a sample of Activity Logs in one of the courses namely; Project Appraisal Course (MG 621). The actual values associated with the predictors extracted from Moodle logs were counted using an excel function "=SUMPRODUCT (--(ISNUMBER (SEARCH ("resource views", E2:E84))))". The results of the count formed one component of a pair. The other component of the pair was formed by the students' grade scored in a course. Table 1, shows the results of the counts of each predictor variable for one of the course namely; Project Appraisal Course (MG 621).

\begin{tabular}{|c|c|c|c|c|c|c|c|c|}
\hline 4 & A & B & C & D & $E$ & F & G & H \\
\hline 1 & MG 621 & 2014 February $1321: 43$ & 41.222.177.99 & course view & \multicolumn{2}{|c|}{ Project Appraisal } & & \\
\hline 2 & MG 621 & 2014 February $1321: 42$ & 41.222.177.100 & assign view & & & & \\
\hline 3 & MG 621 & 2014 February $1321: 40$ & 41.222 .177 .97 & course view & \multirow{2}{*}{\multicolumn{2}{|c|}{ Project Appraisal }} & & \\
\hline 4 & MG 621 & 2014 February $1314: 02$ & 41.73 .220 .6 & assign view & & & & \\
\hline 5 & MG 621 & 2014 February 13 14:01 & 41.73 .220 .6 & course view & \multicolumn{2}{|c|}{ Project Appraisal } & & \\
\hline 6 & MG 621 & 2014 February $1314: 01$ & 41.204 .142 .143 & course view & \multicolumn{3}{|c|}{ Project Appraisal } & \\
\hline 7 & MG 621 & 2014 February 13 12:01 & 41.93 .33 .253 & resource view & \multicolumn{4}{|c|}{ Project Risk and Sensitivity Analysis } \\
\hline 8 & MG 621 & 2014 February $1310: 52$ & 197.186.177.77 & course view & Project & praisal & & \\
\hline 9 & MG 621 & 2014 February $1310: 44$ & 41.93 .33 .253 & page view & \multicolumn{3}{|c|}{ Financial Based Techniques } & \\
\hline 10 & MG 621 & 2014 February $1310: 44$ & 41.93 .33 .253 & course view & \multicolumn{3}{|c|}{ Project Appraisal } & \\
\hline 11 & MG 621 & 2014 February 13 10:21 & 41.204.133.233 & course view & \multicolumn{3}{|c|}{ Project Appraisal } & \\
\hline 12 & MG 621 & 2014 February $139: 47$ & 41.222 .180 .108 & assign view & & & & \\
\hline 13 & MG 621 & 2014 February $138: 46$ & 41.204 .133 .233 & course view & \multicolumn{3}{|c|}{ Project Appraisal } & \\
\hline 14 & MG 621 & 2014 February 13 8:33. & 41.204.140.8 & page view & \multicolumn{4}{|c|}{ Project Impact and Beneficiary Assessments } \\
\hline 15 & MG 621 & 2014 February $137: 44$ & 41.204 .140 .8 & resource view & \multicolumn{4}{|c|}{ Project Risk and Sensitivity Analysis } \\
\hline 16 & MG 621 & 2014 February 1 & 8 & course view & \multicolumn{2}{|c|}{ Project Appraisal } & & \\
\hline 17 & MG 621 & 2014 February $137: 38$ & 41.222 .180 .108 & course view & \multirow{2}{*}{\multicolumn{2}{|c|}{ Project Appraisal }} & & \\
\hline 18 & MG 621 & 2014 February $131: 12$ & 197.187.242.15 & assign view & & & & \\
\hline 19 & MG 621 & 2014 February $1222: 59$ & 197.221 .196 .253 & resource view & \multicolumn{4}{|c|}{ Introduction to Project Appraisal PPT } \\
\hline 20 & MG 621 & 2014 February 122225 & 197.187 .196 .39 & course view & \multicolumn{3}{|c|}{ Project Appraisal } & \\
\hline 21 & MG 621 & 2014 February 122222 & 197.187.196.39 & page view & \multicolumn{3}{|c|}{ Types of risks analysis } & \\
\hline 22 & MG 621 & 2014 February $1222: 18$ & 41.73 .220 .88 & course view & \multicolumn{3}{|c|}{ Project Appraisal } & \\
\hline 23 & MG 621 & 2014 February $1222: 01$ & 41.204 .143 .165 & course view & \multicolumn{3}{|c|}{ Project Appraisal } & \\
\hline 24 & MG 621 & 2014 February $1219: 58$ & 197.250 .4 .16 & page view & \multicolumn{3}{|c|}{ EIA and Technical Assessment } & \\
\hline 25 & MG 621 & 2014 February 1219.53 & 197.250 .4 .16 & resource view & \multicolumn{4}{|c|}{ Introduction to Project Appraisal PPT } \\
\hline 26 & MG 621 & 2014 February $1219: 53$ & 197.250 .4 .16 & resource view & \multicolumn{4}{|c|}{ Sample Project Appraisal_Feasibility Report } \\
\hline 27 & MG 621 & 2014 February $1219: 53$ & 197.250 .4 .16 & course view & \multicolumn{2}{|c|}{ Project Appraisal } & & \\
\hline 28 & MG 621 & 2014 February 12 10:39 & 41.222.181.144 & assign view & & & & \\
\hline 29 & MG 621 & 2014 February 12 10:37 & 41.222.181.139 & course view & \multicolumn{2}{|c|}{ Project Appraisal } & & \\
\hline 30 & MG 621 & 2014 February 10 10:32 & 41.204 .135 .32 & course view & \multicolumn{2}{|c|}{ Project Appraisal } & & \\
\hline 31 & MG 621 & 2014 February 7 20:02 & 197.221 .193 .95 & page view & \multicolumn{3}{|c|}{ Project Selection - VDEO CLIP } & \\
\hline 32 & MG 621 & 2014 February $720: 01$ & 197.221.193.95 & course view & \multicolumn{3}{|c|}{ Project Appraisal } & \\
\hline
\end{tabular}

Figure 3: Sample Activity Logs in Project Appraisal Course (MG 621) 
International Journal of Artificial Intelligence and Applications (IJAIA), Vol.8, No.2, March 2017

Table 1: Summary of Activity Counts Obtained from Project Appraisal Course

\begin{tabular}{|c|c|c|c|c|c|}
\hline \multirow[b]{2}{*}{ No. } & \multicolumn{4}{|c|}{ Predictorvariables } & \multirow{2}{*}{$\begin{array}{c}\text { Course } \\
\text { Grade } \\
\text { Score }\end{array}$} \\
\hline & $\begin{array}{l}\text { Login } \\
\text { Sessions }\end{array}$ & $\begin{array}{l}\text { Resource } \\
\text { Views }\end{array}$ & $\begin{array}{l}\text { Forum } \\
\text { Participation }\end{array}$ & Undergraduate GPA & \\
\hline 1 & 204 & 35 & 0 & 2.1 & $\mathrm{~B}$ \\
\hline 2 & 157 & 154 & 0 & 3.7 & B \\
\hline 3 & 81 & 77 & 1 & 3.3 & $\mathrm{~B}+$ \\
\hline 4 & 27 & 5 & 0 & 4.2 & B \\
\hline 5 & 67 & 54 & 4 & 2.5 & $\mathrm{C}$ \\
\hline 6 & 33 & 55 & 0 & 2.9 & B \\
\hline 7 & 106 & 12 & 1 & 3.4 & $\mathrm{~B}+$ \\
\hline 8 & 86 & 65 & 0 & 2.5 & B \\
\hline 9 & 110 & 104 & 1 & 3.5 & A \\
\hline 10 & 46 & 70 & 1 & 3.2 & $\mathrm{~B}+$ \\
\hline 11 & 27 & 36 & 0 & 3.8 & $\mathrm{~B}$ \\
\hline 12 & 140 & 56 & 4 & 3.9 & A \\
\hline 13 & 82 & 141 & 5 & 4.1 & $\mathrm{~B}+$ \\
\hline 14 & 19 & 58 & 0 & 3 & $\mathrm{C}$ \\
\hline 15 & 68 & 66 & 3 & 3.5 & B \\
\hline 16 & 190 & 155 & 0 & 2.5 & B \\
\hline 17 & 143 & 93 & 2 & 3 & A \\
\hline 18 & 30 & 49 & 0 & 3 & B \\
\hline 19 & 126 & 69 & 1 & 2.6 & $\mathrm{~B}+$ \\
\hline 20 & 85 & 115 & 2 & 2.7 & $\mathrm{~B}+$ \\
\hline 21 & 32 & 37 & 0 & 3.4 & $\mathrm{C}$ \\
\hline 22 & 56 & 77 & 0 & 3.4 & B \\
\hline 23 & 58 & 159 & 3 & 3.5 & $\mathrm{~B}$ \\
\hline
\end{tabular}

\subsection{Pre-Processing Data}

Before data is presented in MATLAB, they must be transformed in a manner suitable for processing. The pre-processing actions performed in this study were data transformation and data normalization. Data Transformation were done as follows;

Login sessions into ranges of '0-49', '50-99', and '100-above' considered as 'Low', 'Moderate' and 'High' respectively.

Resource views into ranges of '0-49', '50-99', and '100-above' considered as 'Low', 'Moderate' and 'High' respectively.

Forum participation into range of ' 1 - above' considered as 'Participated' and ' 0 ' considered as 'Not participated'.

Undergraduate GPA into ranges of '0.0-3.1', '3.2-3.7', and '3.8-5.0' considered as 'Low', 'Moderate' and 'High' respectively.

Course achievement categorized into 'Risky' status for grades of B, C and D while 'Pass' status for grades of B+ and A. Data normalization were done by equation;

Normalized $=$ data/max $(\operatorname{abs}($ data $(:)))$

\subsection{Building A Neural Network Model}

In order to determine the optimal architecture and learning algorithm, the study examined ten possible neural network model architectures with varied number of hidden neurons in hidden layer and learning algorithm as shown in Table 2. 
International Journal of Artificial Intelligence and Applications (IJAIA), Vol.8, No.2, March 2017

Table 2: Neural Network Models Subjected for Examinations

\begin{tabular}{|l|l|l|l|l|}
\hline No. & Model architecture & \multicolumn{4}{|l|}{ Training algorithms } \\
\hline 1 & $4: 2: 1$ & BR & GDM & GD \\
\hline 2 & $4: 4: 1$ & BR & GDM & GD \\
\hline 3 & $4: 6: 1$ & BR & GDM & GD \\
\hline 4 & $4: 8: 1$ & BR & GDM & GD \\
\hline 5 & $4: 10: 1$ & BR & GDM & GD \\
\hline 6 & $4: 12: 1$ & BR & GDM & GD \\
\hline 7 & $4: 14: 1$ & BR & GDM & GD \\
\hline 8 & $4: 16: 1$ & BR & GDM & GD \\
\hline 9 & $4: 18: 1$ & BR & GDM & GD \\
\hline 10 & $4: 20: 1$ & BR & GDM & GD \\
\hline
\end{tabular}

\subsection{TRAINING NETWORK}

Training a neural network uses training sets. Training sets build the predictive model by learning the relationship existing between inputs and outputs. At this stage, each of the neural network models under examination was passed through several trainings using 1000 as the maximum number of epochs. In each training, the average MSE and $\mathrm{R}^{2}$ was observed and a training that appeared to provide minimum average MSE and $\mathrm{R}^{2}$ was recorded for comparing it with other neural network models MSE and $\mathrm{R}^{2}$.

\subsection{NETWORK TESTING}

This is the final step in modelling. It deals with evaluation of the model found to provide the best MSE and $\mathrm{R}^{2}$ in training stage, using data not participated in training known as testing data or outof-sample data. It is only one model with best results which is supposed to be tested, but for the purpose of discussion, all the ten designed models were tested. Also, the process of training and testing were done concurrently such that once the network is trained in the first iteration using the training set then were tested with its corresponding testing sets. This process was repeated until the sixth iteration.

\subsection{6-Fold CROSS VALIDATION}

In order to obtain pairs to be used for training and testing, 6-fold cross validation was used, the dataset was partitioned into 6 folds of 13 datasets in each fold. Partitioning using K-fold cross validation were done in MATLAB software shown by Equation 2 after loading all the datasets.

$\mathrm{Cv}=$ cvpartition $(78$, 'kfold', 6

In each iteration $(\mathrm{K}=1,2,3,4,5,6)$, sixty five (65) data samples were used for training and thirteen (13) data samples for testing. The training MSE and testing MSE obtained in each iteration were recorded. The average MSE during training and testing were obtained using Equation 3.

Average MSE $=\frac{1}{6} \sum_{i=1}^{6} A_{i}$

Where: A is the MSE for each iteration.

Figure 4, shows the graphical representation of the 6-fold cross validation used in this study. 
International Journal of Artificial Intelligence and Applications (IJAIA), Vol.8, No.2, March 2017

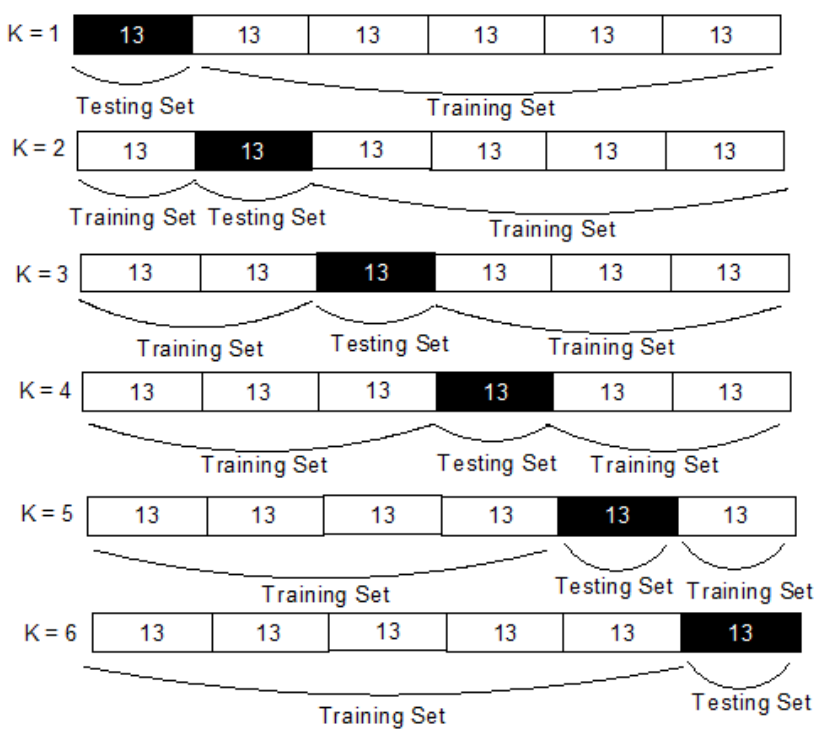

\section{RESULTS}

Figure 4: 6-fold Cross Validation

\subsection{Results DuRing Training}

The results of MSE and $\mathrm{R}^{2}$ during training for each of the iteration in all the network models were recorded. The intention was to find a model architecture and learning algorithm that provide minimum MSE during training. Such model has high ability of prediction when data not participated in the training is used. Table 3, Table 4 and Table 5 show the detailed results for each iteration and average values for MSE and $\mathrm{R}^{2}$ during training using BR, GDM and GD learning algorithms.

Table 3: MSE and $\mathrm{R}^{2}$ Results during Training with BR Learning Algorithm

\begin{tabular}{|c|c|c|c|c|c|c|c|c|}
\hline \multirow{2}{*}{$\begin{array}{l}\text { Model } \\
\text { Archite- } \\
\text { cture }\end{array}$} & \multicolumn{6}{|c|}{ Iteration (k) } & \multirow{2}{*}{$\begin{array}{l}\text { Average } \\
\text { Training } \\
\text { MSE }\end{array}$} & \multirow{2}{*}{$\begin{array}{l}\text { Average } \\
\text { Training } \\
\mathbf{R}^{2}\end{array}$} \\
\hline & 1 & 2 & 3 & 4 & 5 & 6 & & \\
\hline $4: 2: 1$ & 0.0176 & 0.0177 & 0.0172 & 0.0165 & 0.0169 & 0.0171 & 0.0172 & 0.9305 \\
\hline $4: 4: 1$ & 0.0157 & 0.0188 & 0.0182 & 0.0197 & 0.0173 & 0.0143 & 0.0173 & 0.9300 \\
\hline $4: 6: 1$ & 0.0169 & 0.0167 & 0.0157 & 0.0178 & 0.0197 & 0.0157 & 0.0171 & 0.9308 \\
\hline $4: 8: 1$ & 0.0190 & 0.0170 & 0.0170 & 0.0180 & 0.0177 & 0.0154 & 0.0174 & 0.9297 \\
\hline $4: 10: 1$ & 0.0192 & 0.0175 & 0.0179 & 0.0144 & 0.0151 & 0.0180 & 0.0170 & 0.9311 \\
\hline $4: 12: 1$ & 0.0196 & 0.0159 & 0.0172 & 0.0167 & 0.0176 & 0.0171 & 0.0173 & 0.9297 \\
\hline $4: 14: 1$ & 0.0183 & 0.0166 & 0.0201 & 0.0175 & 0.0180 & 0.0137 & 0.0174 & 0.9299 \\
\hline $4: 16: 1$ & 0.0170 & 0.0198 & 0.0171 & 0.0186 & 0.0193 & 0.0140 & 0.0176 & 0.9287 \\
\hline $4: 18: 1$ & 0.0187 & 0.0164 & 0.0168 & 0.0174 & 0.0146 & 0.0193 & 0.0172 & 0.9303 \\
\hline $4: 20: 1$ & 0.0173 & 0.0181 & 0.0247 & 0.0181 & 0.0167 & 0.0142 & 0.0182 & 0.9265 \\
\hline
\end{tabular}


International Journal of Artificial Intelligence and Applications (IJAIA), Vol.8, No.2, March 2017

Table 4: MSE and $\mathrm{R}^{2}$ Results during Training with GDM Learning Algorithm

\begin{tabular}{|c|c|c|c|c|c|c|c|c|}
\hline \multirow{2}{*}{$\begin{array}{l}\text { Model } \\
\text { Archite- } \\
\text { cture }\end{array}$} & \multicolumn{6}{|c|}{ Iteration (k) } & \multirow{2}{*}{$\begin{array}{l}\text { Average } \\
\text { Training } \\
\text { MSE }\end{array}$} & \multirow{2}{*}{$\begin{array}{l}\text { Average } \\
\text { Training } \\
\mathbf{R}^{2}\end{array}$} \\
\hline & 1 & 2 & 3 & 4 & 5 & 6 & & \\
\hline $4: 2: 1$ & 0.0235 & 0.0204 & 0.0380 & 0.0329 & 0.0314 & 0.0291 & 0.0292 & 0.8883 \\
\hline $4: 4: 1$ & 0.0409 & 0.0145 & 0.0132 & 0.0152 & 0.0168 & 0.0149 & 0.0192 & 0.9280 \\
\hline $4: 6: 1$ & 0.0203 & 0.0166 & 0.0151 & 0.0132 & 0.0155 & 0.0296 & 0.0184 & 0.9315 \\
\hline $4: 8: 1$ & 0.0256 & 0.0230 & 0.0249 & 0.0383 & 0.0245 & 0.0294 & 0.0276 & 0.9281 \\
\hline $4: 10: 1$ & 0.0418 & 0.0224 & 0.0183 & 0.0374 & 0.0245 & 0.0229 & 0.0279 & 0.9274 \\
\hline $4: 12: 1$ & 0.0182 & 0.0187 & 0.0136 & 0.0200 & 0.0165 & 0.0161 & 0.0172 & 0.9304 \\
\hline $4: 14: 1$ & 0.0205 & 0.0350 & 0.0249 & 0.0237 & 0.0255 & 0.0299 & 0.0266 & 0.9285 \\
\hline $4: 16: 1$ & 0.0264 & 0.0227 & 0.0276 & 0.0358 & 0.0246 & 0.0414 & 0.0297 & 0.8797 \\
\hline $4: 18: 1$ & 0.0375 & 0.0273 & 0.0243 & 0.0313 & 0.0207 & 0.0321 & 0.0289 & 0.8933 \\
\hline $4: 20: 1$ & 0.0235 & 0.0204 & 0.0380 & 0.0329 & 0.0314 & 0.0291 & 0.0292 & 0.8883 \\
\hline
\end{tabular}

Table 5: MSE and $\mathrm{R}^{2}$ Results during Training with GD Learning Algorithm

\begin{tabular}{|c|c|c|c|c|c|c|c|c|}
\hline \multirow{2}{*}{$\begin{array}{l}\text { Model } \\
\text { Archite } \\
\text { cture }\end{array}$} & \multicolumn{6}{|c|}{ Iteration (k) } & \multirow{2}{*}{$\begin{array}{l}\text { Average } \\
\text { Training } \\
\text { MSE }\end{array}$} & \multirow{2}{*}{$\begin{array}{l}\text { Average } \\
\text { Training } \\
\mathbf{R}^{2}\end{array}$} \\
\hline & 1 & 2 & 3 & 4 & 5 & 6 & & \\
\hline $4: 2: 1$ & 0.0274 & 0.0282 & 0.0301 & 0.0267 & 0.0309 & 0.0271 & 0.0284 & 0.8851 \\
\hline $4: 4: 1$ & 0.0234 & 0.0379 & 0.0207 & 0.0263 & 0.0273 & 0.0315 & 0.0278 & 0.8868 \\
\hline $4: 6: 1$ & 0.0358 & 0.0284 & 0.0319 & 0.0206 & 0.0252 & 0.0237 & 0.0276 & 0.8883 \\
\hline $4: 8: 1$ & 0.0408 & 0.0346 & 0.0365 & 0.0470 & 0.0263 & 0.0273 & 0.0354 & 0.8575 \\
\hline $4: 10: 1$ & 0.0330 & 0.0227 & 0.0280 & 0.0236 & 0.0276 & 0.0313 & 0.0277 & 0.8876 \\
\hline $4: 12: 1$ & 0.0219 & 0.0294 & 0.0233 & 0.0411 & 0.0378 & 0.0251 & 0.0298 & 0.8787 \\
\hline $4: 14: 1$ & 0.0285 & 0.0271 & 0.0299 & 0.0298 & 0.0334 & 0.0257 & 0.0291 & 0.8823 \\
\hline $4: 16: 1$ & 0.0338 & 0.0205 & 0.0287 & 0.0512 & 0.0225 & 0.0225 & 0.0299 & 0.8796 \\
\hline $4: 18: 1$ & 0.0359 & 0.0228 & 0.0316 & 0.0204 & 0.0289 & 0.0268 & 0.0277 & 0.8876 \\
\hline $4: 20: 1$ & 0.0507 & 0.0280 & 0.0455 & 0.0211 & 0.0399 & 0.0258 & 0.0352 & 0.8573 \\
\hline
\end{tabular}

From the table 3, it can be noted that the table with architecture of 4:10:1 trained with BR had least MSE of 0.0170 and high $\mathrm{R}^{2}$ of 0.93 during training compared to other models. Therefore chosen as the best model.

\subsection{Results During Testing}

The results of MSE and $\mathrm{R}^{2}$ during testing for each of the iteration in all the neural network models were recorded. Table 6 , show the results for individual iteration and average values for MSE and $\mathrm{R}^{2}$ in testing using BR learning algorithms. 
International Journal of Artificial Intelligence and Applications (IJAIA), Vol.8, No.2, March 2017

Table 6: MSE and $\mathrm{R}^{2}$ Results during Testing with BR Learning Algorithm

\begin{tabular}{|c|c|c|c|c|c|c|c|c|}
\hline \multirow{2}{*}{$\begin{array}{l}\text { Model } \\
\text { Archit } \\
\text { ecture }\end{array}$} & \multicolumn{6}{|c|}{ Iteration (k) } & \multirow{2}{*}{$\begin{array}{l}\text { Average } \\
\text { Training } \\
\text { MSE }\end{array}$} & \multirow{2}{*}{$\begin{array}{l}\text { Average } \\
\text { Training } \\
\mathbf{R}^{2}\end{array}$} \\
\hline & 1 & 2 & 3 & 4 & 5 & 6 & & \\
\hline $4: 2: 1$ & 0.0145 & 0.0200 & 0.0233 & 0.0230 & 0.0240 & 0.0200 & 0.0208 & 0.9139 \\
\hline $4: 4: 1$ & 0.0304 & 0.0161 & 0.0147 & 0.0106 & 0.0244 & 0.0314 & 0.0213 & 0.9161 \\
\hline $4: 6: 1$ & 0.0221 & 0.0284 & 0.0270 & 0.0208 & 0.0102 & 0.0250 & 0.0222 & 0.9066 \\
\hline $4: 8: 1$ & 0.0194 & 0.0202 & 0.0237 & 0.0155 & 0.0171 & 0.0281 & 0.0207 & 0.9156 \\
\hline $4: 10: 1$ & 0.0110 & 0.0225 & 0.0166 & 0.0279 & 0.0277 & 0.0116 & 0.0196 & 0.9214 \\
\hline $4: 12: 1$ & 0.0095 & 0.0196 & 0.0188 & 0.0315 & 0.0186 & 0.0203 & 0.0197 & 0.9191 \\
\hline $4: 14: 1$ & 0.0144 & 0.0235 & 0.0133 & 0.0167 & 0.0128 & 0.0411 & 0.0203 & 0.9201 \\
\hline $4: 16: 1$ & 0.0178 & 0.0117 & 0.0189 & 0.0179 & 0.0173 & 0.0405 & 0.0207 & 0.9170 \\
\hline $4: 18: 1$ & 0.0141 & 0.0247 & 0.0176 & 0.0195 & 0.0301 & 0.0180 & 0.0207 & 0.9164 \\
\hline $4: 20: 1$ & 0.0193 & 0.0149 & 0.0216 & 0.0137 & 0.0253 & 0.0326 & 0.0212 & 0.9176 \\
\hline
\end{tabular}

\subsection{Prediction Accuracy Of The Best Model In Percentage}

Using test data percentage accuracy of the selected model was calculated. The 'Pass' had a representation of 2 while 'Risky' students represented by 1 in MATLAB, it was expected that the trained neural network model would be predicting values of 2 and 1 accordingly. But, it is difficult for the trained model to exactly reach these values. Therefore, a tolerance of \pm 0.5 was set such that when the difference between target and predicted is within tolerance, then an instance was regarded as 'successful'. Finally, a total of 61 students' instances were found to have 'successful' comment out of 78 students' instances resulting to $78 \%$ of all students' instances.

\subsection{Representation Of Correlation Between Desired And Predicted Values}

Figure 5 indicates a graphical representation of $\mathrm{R}^{2}$ of the best model. It shows the strength of correlation between the targets and the predicted achievements in each iteration/round of the $\mathrm{K}$ fold.
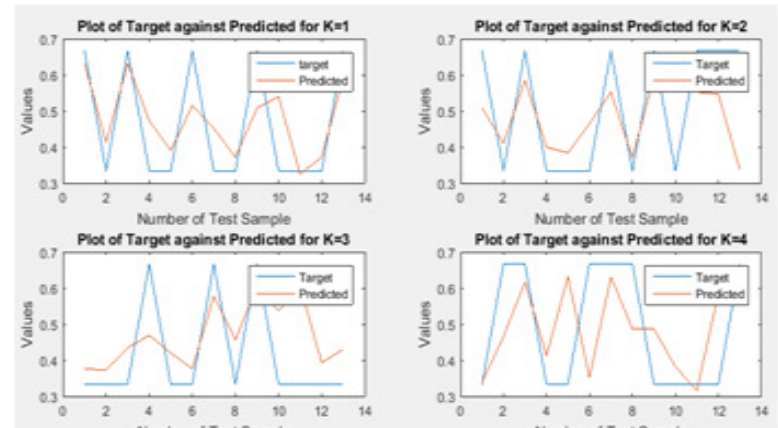

Number of Test Sample

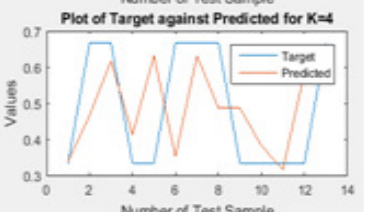

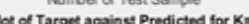
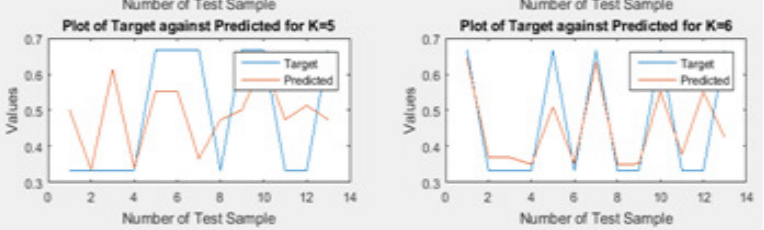

Figure 5: Comparison of Target and Predicted Data in Testing for Model 4:10:1 


\subsection{Neural Network Prediction Model}

Figure 6 is the neural network model generated in MATLAB. It shows how input parameters are connected to hidden layers, and further the way hidden layers are connected to the output layer.

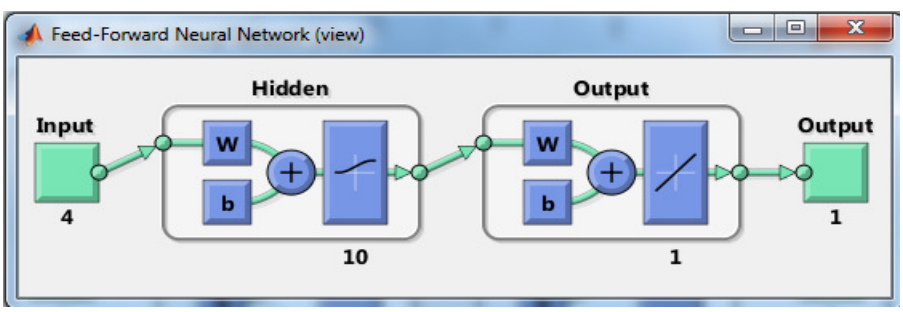

Figure 6: Neural Network Model Created in MATLAB

\subsection{The Proposed Neural Network Model}

Using model generated in MATLAB indicated by Figure 6, a simple neural network model was drawn as shown in Figure 7. It shows ten hidden neurons at hidden layer, four neurons at input layer and one at output layer. It resembles the abstract model indicated by Figure 1 as proposed.

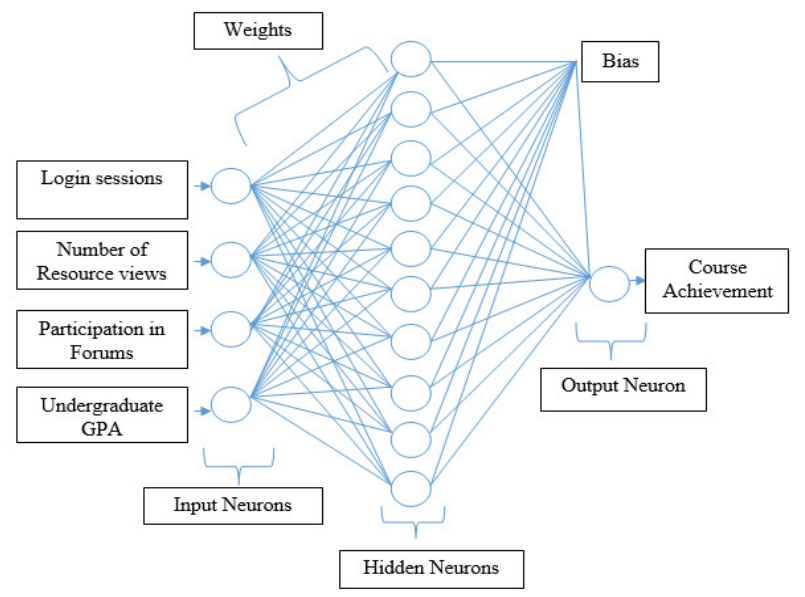

Figure 7: Proposed Artificial Neural Network Model

\section{RESULTS DISCUSSION}

The study aimed at finding and validating a neural network model to be used for prediction of students' achievements in blended courses for the context of the UDSM. In this section, key findings are discussed by focusing on two perspectives: one is the difference in values of MSE obtained during training and testing (validation), and students' usage levels in Moodle.

\subsection{MSE On TeSting And Training Sets}

In this study, it was expected that any model with small value of MSE on training would result into small value of MSE on testing. This appeared to be the case for the present study. For example, the model found to be the best in the present study resulted into MSE value of 0.0170 during training, which is smaller than MSE of 0.0196 obtained during testing. This findings agree with majority of other studies conducted in similar area such as in [12] and in [17]. For stance, a 
International Journal of Artificial Intelligence and Applications (IJAIA), Vol.8, No.2, March 2017

study conducted by [12] obtained MSE of 0.017 during training than what obtained in testing of 0.0191 when developing a prediction model of one thousands students' results in higher education. The best neural network model found to have 7:50:400:3 architecture, meaning that it had 7 input neurons, first hidden layer with 50 neurons, a second hidden layer with 400 neurons and an output layer with 3 neurons.

\subsection{STUdents' USAGE LeVEls In MOODLE}

The results showed that the main blended learning activities were reading and accessing course materials. Even though courses had platform for peer collaborations and collaborations with their educators, students did not often appear to seek such collaborations as is supposed be in their blended learning. They mostly preferred reading course materials provided by their educators on Moodle, but they did not always post, read or respond to messages in discussions. The findings agree with many studies conducted in the same area. Examples are seen on studies conducted in higher education institutions in sub-Saharan Africa [18].

\section{Conclusions}

At first, various literatures were reviewed to find out key predictors of students' achievement in blended courses. Key predictors identified were found to be login sessions, number of viewed resources, forum participation frequency and the undergraduate GPA. Utilizing data gathered based on predictor variable and output, the study examined ten possible neural network models. The models examined had different architectures; meaning varied number of hidden neurons in hidden layer. MSE and R2 were used to measure and compare the predictive ability of the models. A model is said to have better performance than others if it generates smaller MSE value and high R2 on training. Therefore, a model with 4:10:1 architecture trained with BR was found in this this study to have lower MSE of 0.0170 than other model architectures and high coefficient of determination of 0.93 during training. During testing provided minimum MSE as well, equivalent to $78 \%$. Therefore, selected as the best model architecture with the best predictive ability than other examined models.

\section{REFERENCES}

[1] O. E. Obadara, "Effect of Learning Management System (LMS) on Students' Academic Performance in University of Lagos, Nigeria," Int. J. Educ. Found. Manag., vol. 2, no. 1, pp. 25-33, 2014.

[2] Z. F. Muhsen, A. Maaita, A. Odah, and A. Nsour, "Moodle and E-Learning Tools," Int. J. Mod. Educ. Comput. Sci., vol. 5, no. 6, pp. 1-8, Jul. 2013.

[3] Moodle, "Moodle statistics," 2014. [Online]. Available: http://moodle.net/stats/. [Accessed: 29-Sep2014].

[4] H. Twakyondo and M. Munaku, "Experience of Course Migration from Blackboard to Moodle LMS - A Case Study from UDSM,” Int. J. Comput. ICT Res., vol. 6, no. 2, pp. 33-45, 2012.

[5] R. Cristobal, P. G. Espejo, Z. Amelia, J. R. Romero, and V. Sebastian, "Web Usage Mining for Predicting Final Marks of Students that Use Moodle Courses," Comput. Appl. Eng. Educ., vol. 21, no. 1, pp. 135-146, 2013.

[6] I.-H. Jo, Y. Park, J. Kim, and J. Song, "Analysis of Online Behavior and Prediction of Learning Performance in Blended Learning Environments," Educ. Technol. Int., vol. 15, no. 2, pp. 71-88, 2014.

[7] F. Mödritscher, M. Andergassen, and G. Neumann, "Dependencies Between E-learning Usage Patterns and Learning Results," in Proceedings of the 13th International Conference on Knowledge Management and Knowledge Technologies, 2013, pp. 1-8.

[8] M. Tayebinik and M. Puteh, "Blended Learning or E-learning?.," Int. Mag. Adv. Comput. Sci. Telecommun., vol. 3, no. 1, pp. 103-110, 2012. 
International Journal of Artificial Intelligence and Applications (IJAIA), Vol.8, No.2, March 2017

[9] J. Lungo, “Optimization of Learning Management Systems Through Systems Integration: The Case of Moodle and Zalongwa Software," in Ist International conference of the AVU, November 20-22, 2013, 2013.

[10] F. Azizan, "Blended Learning in Higher Education Institution in Malaysia," in Proceedings of Regional Conference on Knowledge Integration in ICT 2010, 2010, pp. 454-466.

[11] A. I. Obasa, A. A. Eludire, and T. A. Ajao, "A Comparative Study of Synchronous and Asynchronous E-Learning Resources,” Int. J. Innov. Res. Sci. Eng. Technol., vol. 2, no. 11, pp. 5938-5946, 2013.

[12] B. Oancea, R. Dragoescu, and S. Ciucu, "Predicting Students' Results in Higher Education Using Neural Networks," in International Conference on Applied Information and Communication Technology, 2013, pp. 190-193.

[13] S. A. Naser, I. Zaqout, M. A. Ghosh, R. Atallah, and E. Alajrami, "Predicting Student Performance Using Artificial Neural Network : in the Faculty of Engineering and Information Technology," Int. J. Hybrid Inf. Technol., vol. 8, no. 2, pp. 221-228, 2015.

[14] G. M. Kanakana and A. O. Olanrewaju, "Predicting Student Performance in Engineering Education Using an Artificial Neural Network at Tshwane Univerity of Technology," in ISEM 2011 Proceedings, 2011, pp. 1-17.

[15] K. Kumar and G. S. M. Thakur, "Advanced Applications of Neural Networks and Artificial Intelligence: A Review,” Int. J. Inf. Technol. Comput. Sci., vol. 4, no. 6, pp. 57-68, 2012.

[16] C. Romero, M.-I. López, J.-M. Luna, and V. Sebastián, "Predicting Students' Final Performance from Participation in On-line Discussion Forums,” Comput. Educ., vol. 68, pp. 458-472, 2013.

[17] J. Chen, H. Hsieh, and Q. H. Do, "Predicting Student Academic Performance: A Comparison of Two Meta-Heuristic Algorithms Inspired by Cuckoo Birds for Training Neural Networks," Algorithms, vol. 7, no. 4, pp. 538-553, 2014.

[18] Mtebe, "Making Learning Management System Success for Blended Learning in Higher Education in sub-Saharan Africa Joel S . Mtebe," 2013.

[19] M. H. Al Shamisi, A. H. Assi, and H. Hejase, "Using MATLAB to Develop Artificial Neural Network Models for Predicting Global Solar Radiation in Al ain City-UAE," in Engineering Education and Research Using MATLAB, A. H. Assi, Ed. Rijeka, Croatia: InTech, 2011, pp. 219238.

\section{AUTHORS}

Eliah Kazumali received Masters of Science in Computer Science from the University of Dar es salaam in Tanzania. He is currently working as Assistance Lecturer at Teofilo Kisanji University in Tanzania, also a member of eLearning Research Group (eLRG) at the University of Dar es Salaam. His research interests include; Artificial intelligence, eLearning, neural networks and web development

Eng. Dr. Ellen Kalinga received B.E. degree in Electrical and Electronics Engineering from the University of Mysore India in 1990 and Master of Science (Electronics \& IT of the University of Dar as Salaam in 2002. In 2011, she also received her Ph.D. degree in Computer Engineering and Information Technology from the University of Dar as Salaam Tanzania. Currently she is a Lecturer at the University of Dar es Salaam.
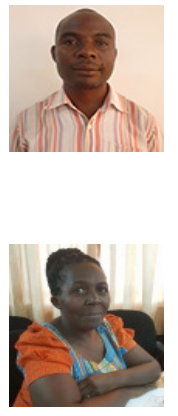